\title{
24-hour greenhouse temperature prediction model based on the weather
}

\section{forecast}

\author{
Wang-Jun ${ }^{1, a}$, Yu-Haiye ${ }^{1, a}$ \\ ${ }^{1}$ College of Biological and Agricultural Engineering, Jilin University, Changchun 130022, China \\ awangjun_jledu@163.com
}

Keywords: Maximum temperature, Weather forecast, Correlation coefficient, Prediction Model

\begin{abstract}
The relationship of maximum temperature、minimum temperature mean temperature and 24-hour temperature between inside and outside greenhouse based on the weather forecast were studied in this paper. The established prediction models were tested and the error was analyzed. Correlation coefficients of maximum temperature minimum temperature and mean temperature between inside and outside greenhouse are 0.9059、0.9472 and 0.9627 separately, Correlation coefficients of 24-hour temperature between inside and outside greenhouse are from 0.8797 to 0.9868 , all passed the test of significance at the 0.01 level, all the standard error/mean of prediction models are less than 15\%. Correlation coefficients between the real value and predicted value are from 0.8916 to 0.9525 , the analysis shows that the prediction models have good predict performances, so as to provide some help for the regulation of greenhouse environment.
\end{abstract}

\section{Introduction}

At present, the establishment of a solarium/greenhouse attached to a building[1] and a theoretical nongray rigorous model[2], the use of phase change materials[3]、 biomass energy[4] and biological control[5], shows that people pay more and more attention to energy saving, environmental protection and food safety issues. But there is less research on how to calculate temperature in greenhouse take advantage of weather forecast. If we can according to the weather forecast parameters such as the maximum and minimum temperature obtained to predict the temperature inside the greenhouse, then we can take corresponding control measures in advance to make greenhouse environmental conditions be suitable for the need of plant growth.

\section{The Material and Approach of the Experiment}

The experimental greenhouse is in Nanling Campus of Jilin University. With an area of around $200 \mathrm{~m}^{2}$, the experimental greenhouse is an all-glass one, with the side windows on the four side available to be opened. The dominant plant in the greenhouse is cucumber, which is put into the experiment under natural state with the temperature controlled only through the side windows' ventilation and the irritation undertaken in accordance with the humidity of the greenhouse. The experiment picks July $1^{\text {st }}, 2011$ to October $11^{\text {th }}, 2011$ as the main observation period, during which the observation instrument, the PC-3 type portable automatic weather station placed in the middle of the greenhouse, has a time interval of $10 \mathrm{~min}$ and an observation height of $1.5 \mathrm{~m}$. Data of outside greenhouse is from Jilin province professional meteorological observatory issued weather forecast. 
This essay utilizes the Microsoft Excel 2003 software to make recording of the observation result, with the simulation result tested and error analyzed by means of the observation material of the greenhouse dated from May $7^{\text {th }}, 2010$ to June $11^{\text {th }}, 2010$.

\section{The Results and Discussion}

The Establishment of the maximum, minimum and mean temperature model in the Greenhouse

With the method of mathematical statistics, the three main weather elements, namely maximum 、 minimum and mean temperature are picked and undertaken relevance and regression analysis with maximum 、 minimum and mean temperature from the Weather Forecast. Following that, the regression model is established correspondingly. The relationship of maximum temperature between inside and outside greenhouse is shown in Figure 1.

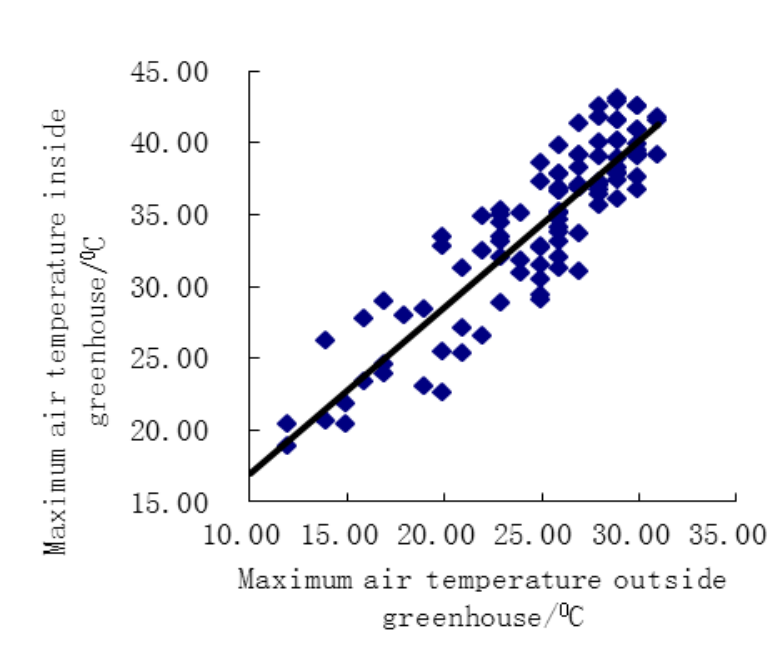

Fig.1 Maximum temperature relationship between inside and outside Fig.2 Minimum temperature relationship between inside and outside greenhouse $\left({ }^{0} \mathrm{C}\right)$

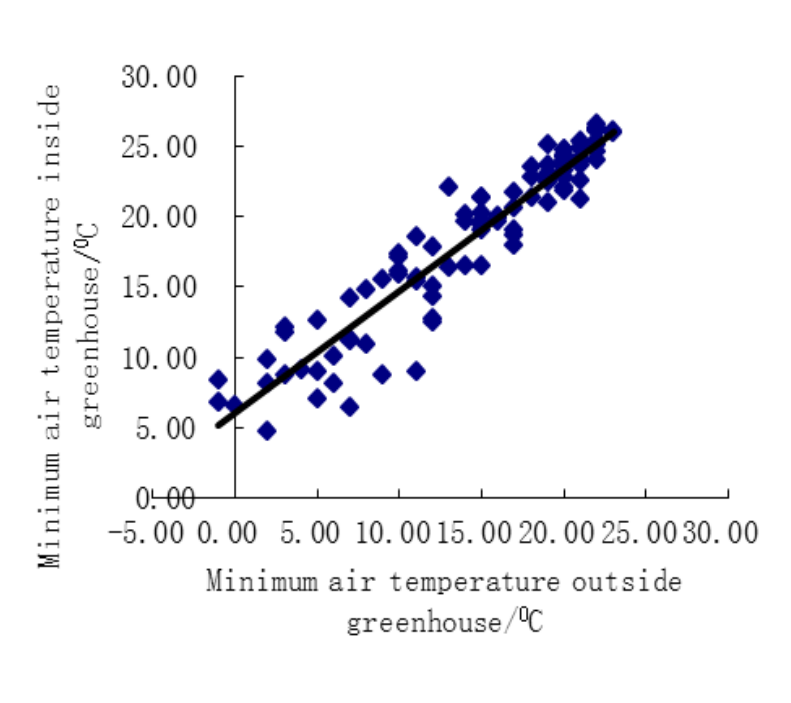

greenhouse $\left({ }^{0} \mathrm{C}\right)$

The unitary linear regression model goes as follows: $y=1.1612 x+5.3353$ in which, $\mathrm{y}$ is maximum temperature in the greenhouse and $\mathrm{x}$ maximum temperature outside the greenhouse.

Figure 2 reveals the relationship of minimum temperature between the inside and outside of the greenhouse. The unitary linear regression model goes as follows: $y=0.8694 x+6.0523$, in which $y$ is minimum temperature in the greenhouse and $\mathrm{x}$ minimum temperature outside the greenhouse.

According to Figure 3, the relationship of the mean temperature between the inside and outside of the greenhouse is shown, in which the mean temperature outside the greenhouse is the average value of maximum and minimum temperature reported in the Weather Forecast. 


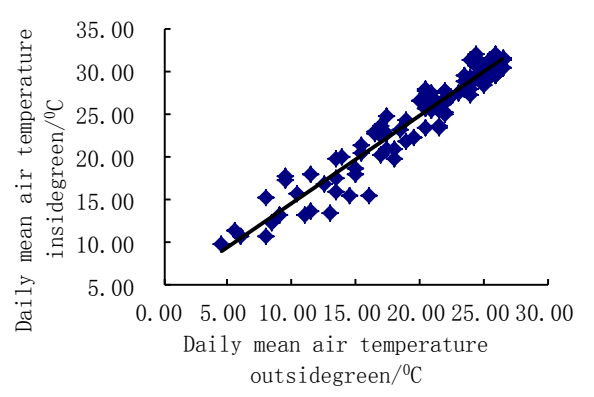

Fig.3 Daily mean temperature relationship between inside and outside greenhouse $\left({ }^{0} \mathrm{C}\right)$

The unitary linear regression model goes as follows: $y=1.0257 x+4.3673$, in which $y$ is the mean temperature in the greenhouse and $\mathrm{x}$ the mean temperature outside the greenhouse.

The co-relation coefficient between maximum, minimum and the mean temperature inside and outside the greenhouse is $0.9059 、 0.9472$ and 0.9627 respectively, each above $0.254=\mathrm{R} 0.01(100)$, and therefore is above the 0.01 significance level. The test is passed, meaning that the two variables have significant co-relationship, and the standard error/average $\mathrm{S} / \bar{y}$ is $0.0778 、 0.1033$ and 0.0664 respectively, which are all lower than $15 \%$, so the regression model can be used to make prediction.

The test of maximum, minimum and mean temperature model in the greenhouse

The regression model of maximum, minimum and mean temperature model in the greenhouse is applied into the observation material of the greenhouse from May $7^{\text {th }}, 2010$ to June $11^{\text {th }}, 2010$ to undertake certification and error analysis. The analytical result is shown as follows. From Table 1, we can see that the true values of the three models have high co-relation coefficient with the predicted value, with lower significance on the 0.05 significance level. Through the above analysis, we come to the conclusion that the model has an excellent performance of prediction. If the short term result of the weather forecast in the weather report is put into the model, maximum, minimum and mean temperature's variation within 1 to 15 days in the greenhouse can be predicted.

Table 1. Comparison of true value and predicted value of maximum air temperature v minimum air temperature and daily mean temperature inside

\begin{tabular}{|c|c|c|c|c|c|}
\hline & $\begin{array}{l}\text { Correlation coefficient } \\
\text { between true value and } \\
\text { predicted value }\end{array}$ & $\begin{array}{l}\text { True value } \\
\text { standard } \\
\text { deviation }\end{array}$ & $\begin{array}{l}\text { Predictive } \\
\text { value standard } \\
\text { deviation }\end{array}$ & $\begin{array}{l}\text { True value } \\
\text { relative } \\
\text { standard } \\
\text { deviation }\end{array}$ & $\begin{array}{l}\text { Predictive } \\
\text { value relative } \\
\text { standard } \\
\text { deviation }\end{array}$ \\
\hline $\begin{array}{l}\text { Minimum air } \\
\text { temperature }\end{array}$ & 0.8916 & 3.8369 & 3.4832 & 0.2279 & 0.1971 \\
\hline
\end{tabular}

The Establishment of the 24 hour Temperature Prediction Model in the Greenhouse 
Maximum temperature generally happens on 14 o'clock, with minimum temperature before the sunrise, so that maximum temperature predicted by the weather forecast is set as the temperature on 14 o'clock and minimum as that on 5 o'clock in the morning, with that in other period of time calculated through arithmetic progression. A comparison between the hour temperatures from 0 to 24 o'clock in the greenhouse and those outside the greenhouse reveals the 24 hour temperature prediction model in the greenhouse based on maximum and minimum temperature from the weather forecast. The model has undergone the regression analysis, with the result shown in Table 2 .

Obvious from Table 2 is that all the correlation coefficients are above $R_{0.01}(82)=0.280$, thereby on the 0.01 significance level, so the test is passed, which means the linear correlation between the two variables is quite significant. The regression analysis shows $\mathrm{S} / \bar{y}$ all lower than $15 \%$, so the regression model can be used to make prediction.

Table 2. The temperature prediction model 、 correlation coefficient 、 comparison of true value and predicted value of 24 hours inside greenhouse based on weather report maximum air temperature and minimum air temperature

\begin{tabular}{|c|c|c|c|c|c|c|c|c|}
\hline Time & Prediction model & $\mathrm{R}$ & $\mathrm{S} / \bar{y}$ & $\begin{array}{l}\text { Correlation } \\
\text { coefficient } \\
\text { between true value } \\
\text { and predicted } \\
\text { value }\end{array}$ & $\begin{array}{l}\text { True value } \\
\text { standard } \\
\text { deviation }\end{array}$ & $\begin{array}{l}\text { Predictive } \\
\text { value } \\
\text { standard } \\
\text { deviation }\end{array}$ & $\begin{array}{l}\text { True } \\
\text { value } \\
\text { relative } \\
\text { standard } \\
\text { deviation }\end{array}$ & $\begin{array}{l}\text { Predictive } \\
\text { value relative } \\
\text { standard } \\
\text { deviation }\end{array}$ \\
\hline $0: 00$ & $y=0.9195 x+4.4343$ & 0.9531 & 0.0821 & 0.8619 & 4.9539 & 4.5181 & 0.2501 & 0.2200 \\
\hline 1: 00 & $\mathrm{y}=0.9113 \mathrm{x}+4.6885$ & 0.9568 & 0.0813 & 0.8736 & 4.8538 & 4.0191 & 0.2516 & 0.2007 \\
\hline 2: 00 & $y=0.9074 x+4.9310$ & 0.9590 & 0.0821 & 0.8771 & 4.7669 & 3.9827 & 0.2531 & 0.2034 \\
\hline 3: 00 & $\mathrm{y}=0.8911 \mathrm{x}+5.5372$ & 0.9643 & 0.0775 & 0.8685 & 4.6357 & 3.8972 & 0.2516 & 0.2019 \\
\hline 4: 00 & $y=0.8713 x+6.0905$ & 0.9622 & 0.0838 & 0.8642 & 4.5007 & 3.8018 & 0.2500 & 0.2006 \\
\hline 5: 00 & $y=0.8820 x+6.2666$ & 0.9659 & 0.0798 & 0.8682 & 4.5118 & 3.8405 & 0.2496 & 0.2054 \\
\hline 6: 00 & $\mathrm{y}=0.9787 \mathrm{x}+4.1833$ & 0.9678 & 0.0810 & 0.9215 & 4.8518 & 4.2764 & 0.2441 & 0.2231 \\
\hline 7: 00 & $y=1.0666 x+3.1761$ & 0.9673 & 0.0831 & 0.9280 & 5.2649 & 4.6949 & 0.2334 & 0.2256 \\
\hline 8: 00 & $y=1.0088 x+6.7983$ & 0.9386 & 0.0936 & 0.8831 & 5.5141 & 4.4902 & 0.2207 & 0.1817 \\
\hline 9: 00 & $\mathrm{y}=1.1295 \mathrm{x}+5.3979$ & 0.9186 & 0.1116 & 0.8908 & 5.7042 & 5.1014 & 0.2161 & 0.1901 \\
\hline 10: 00 & $\mathrm{y}=1.3371 \mathrm{x}+0.7510$ & 0.9490 & 0.0946 & 0.8771 & 5.5623 & 6.1475 & 0.1940 & 0.2214 \\
\hline 11: 00 & $y=1.3906 x-0.5945$ & 0.9555 & 0.0807 & 0.8804 & 5.6336 & 6.5269 & 0.1876 & 0.2235 \\
\hline 12: 00 & $\mathrm{y}=1.3564 \mathrm{x}+0.1154$ & 0.9438 & 0.0873 & 0.9026 & 5.6562 & 6.5153 & 0.1812 & 0.2113 \\
\hline 13: 00 & $y=1.3694 x-0.4971$ & 0.9235 & 0.0955 & 0.8744 & 6.1015 & 6.7460 & 0.1933 & 0.2096 \\
\hline 14: 00 & $\mathrm{y}=1.2994 \mathrm{x}+0.6381$ & 0.9016 & 0.0967 & 0.8649 & 5.5430 & 6.5597 & 0.1741 & 0.1971 \\
\hline 15: 00 & $y=1.1280 x+5.7569$ & 0.8797 & 0.0964 & 0.8639 & 5.8172 & 5.6076 & 0.1835 & 0.1683 \\
\hline 16: 00 & $y=1.0538 x+6.4417$ & 0.8971 & 0.0890 & 0.8891 & 6.1567 & 5.1616 & 0.2010 & 0.1641 \\
\hline 17: 00 & $y=1.0897 x+3.8709$ & 0.9335 & 0.0794 & 0.8966 & 6.5679 & 5.2620 & 0.2239 & 0.1815 \\
\hline 18: 00 & $y=1.1304 x+0.9600$ & 0.9616 & 0.0688 & 0.9221 & 6.3978 & 5.3849 & 0.2314 & 0.2053 \\
\hline 19: 00 & $y=1.0514 x+1.4384$ & 0.9750 & 0.0521 & 0.9448 & 5.7258 & 4.9446 & 0.2241 & 0.2042 \\
\hline $20: 00$ & $y=0.9979 x+2.1543$ & 0.9780 & 0.0506 & 0.9427 & 5.2185 & 4.6368 & 0.2194 & 0.2008 \\
\hline 21: 00 & $y=0.9789 x+2.4100$ & 0.9782 & 0.0527 & 0.9453 & 5.0059 & 4.4978 & 0.2203 & 0.2020 \\
\hline 22: 00 & $y=0.9678 x+2.6823$ & 0.9826 & 0.0487 & 0.9525 & 4.9943 & 4.4013 & 0.2281 & 0.2033 \\
\hline 23: 00 & $y=0.9776 x+2.5674$ & 0.9854 & 0.0445 & 0.9473 & 4.8755 & 4.4047 & 0.2310 & 0.2093 \\
\hline 24: 00 & $y=0.9656 x+2.9183$ & 0.9868 & 0.0438 & 0.9483 & 4.7783 & 4.3149 & 0.2327 & 0.2104 \\
\hline
\end{tabular}

The Establishment of the 24 hour Temperature Prediction Model in the Greenhouse 
The observation material in the greenhouse where the 24 hour temperature regression model is used from May $7^{\text {th }}, 2010$ to June $11^{\text {th }}, 2010$ is undertaken test and error analysis. The result is shown in Table 2, which shows that the 0-24 o'clock temperature's real values and their predicted values have a significantly high correlation, with lower significance one the 0.05 significance level. Through the analysis, we come to the conclusion that the model has an excellent performance of prediction, which can provide certain help on the variation of the 24 hour temperature in the greenhouse.

\section{Conclusion}

This essay studies the relationship between maximum, minimum and mean temperature in the greenhouse and those in the weather forecast and established the regression model. Further finding is the establishment of the 24-hour temperature prediction model in the greenhouse and through the analysis, we can come to the conclusion that the good prediction performance of the model means that maximum, minimum and mean temperature as well as the 24-hour temperature can be predicted according to the short-and-middle-term weather forecast, so that the corresponding control measures can be implemented to match the microclimate in the greenhouse with the need for the growth of the plants.

\section{References}

[1] Diane Bastien, Andreas K Athienitis. A control algorithm for optimal energy performance of a solarium/greenhouse with combined interior and exterior motorized shading [J]. Energy Procedia, 2012, $30: 995 \sim 1005$.

[2] A Al-Mahdouri, H Gonome, J Okajima,etal.Theoretical and experimental study of solar thermal performance of different greenhouse cladding materials[J]. Solar Energy, 2014, $107: 314 \sim 327$.

[3] Beyza Beyhan, Halime Paksoy, Yildız Daßsgan. Root zone temperature control with thermal energy storage in phase change materials for soilless greenhouse applications[J]. Energy Conversion and Management,2013,74,446 453 .

[4] J A Sa'nchez-Molina, J V Reinoso, F G Acie'n,etal. Development of a biomass-based system for nocturnal temperature and diurnal $\mathrm{CO} 2$ concentration control in greenhouses[J].BIOMASS AND BIOENERGY,2014,67: 60 71.

[5] Nian-Wan Yang, Lian-Sheng Zang, Su Wang,etal. Biological pest management by predators and parasitoids in the greenhouse vegetables in China[J]. Biological Control, 2014, $68: 92 \sim 102$. 